\title{
No clinical benefit from gender-specific total knee replacement implants: a systematic review
}

\author{
Elliot Sappey-Marinier ${ }^{1, *}$, John $\operatorname{Swan}^{1}$, Cécile Batailler ${ }^{1}$, Elvire Servien ${ }^{1,2}$, and Sébastien Lustig ${ }^{1,3}$ \\ ${ }^{1}$ FIFA Medical Center of Excellence, Department of Orthopaedic Surgery and Sports Medicine, Croix-Rousse Hospital, \\ Hospices Civils de Lyon, 69004 Lyon, France \\ 2 LIBM - EA 7424, Interuniversity Laboratory of Biology of Mobility, Claude Bernard Lyon 1 University, 69100 Villeurbanne, France \\ 3 Univ. Lyon, Claude Bernard Lyon 1 University, IFSTTAR, LBMC UMR_T9406, 69622 Lyon, France
}

Received 27 April 2020, Accepted 27 May 2020, Published online 3 July 2020

\begin{abstract}
Introduction: Total knee arthroplasty (TKA) remains the treatment of choice for severe osteoarthritis of the knee and nearly $60 \%$ of patients undergoing TKA are women. Females present three notable anatomic differences. Thus, gender-specific (GS) components were introduced to accommodate the females' anatomic differences. No systematic review has been published since 2014. The aim of this study was to perform a recent systematic review of the literature to determine whether there is any clinical benefit of gender-specific implants compared to conventional unisex implants in total knee arthroplasty (TKA). Methods: This study included prospective randomized controlled trials (PRCTs) comparing clinical and radiological outcomes, and complications in TKA with gender-specific implants and conventional implants. All studies had a minimum follow-up of two years. Results: Three PRCTs published between 2010 and 2012 were included. These studies showed a low risk of bias and were of very high quality. We did not find superior clinical outcomes for gender-specific prostheses compared to conventional prostheses. However, gender-specific TKA reduced the number of patients with femoral component overhang compared to conventional TKA. Conclusion: In our systematic review, despite a lower overhang rate, gender-specific implants in female TKA showed no clinical benefit over standard unisex implants. Good clinical results with significant improvement were observed with both designs. There is a notable absence of new studies on this subject in recent years, and further research needs to be performed using various gender-specific implant designs to further define the role of gender-specific implants. Level of evidence: Systematic review, Level IV
\end{abstract}

Key words: Total knee arthroplasty, Unisex design, Gender-specific design, Total knee replacement, Systematic review.

\section{Introduction}

Total knee arthroplasty (TKA) remains the treatment of choice for severe osteoarthritis of the knee [1] and nearly $60 \%$ of patients undergoing TKA are women [2-4]. Outcomes of TKA are influenced by several factors. Indeed, many discussions have focused on the effects of gender on the results of TKA [5-8]. Three notable anatomic differences in the females are well documented [9-12]. Women have a less prominent anterior condyle $[13,14]$, an increased quadriceps angle ( $Q$ angle) $[15,16]$, and a reduced mediolateral (ML)/anteroposterior (AP) aspect ratio [9, 17]. It has been emphasized that standard knee prostheses may not exactly match the native anatomy in female and male knees [18, 19]. This potential femoral component overhang may influence postoperative knee pain or reduce range of motion $[10,20,21]$.

\footnotetext{
*Corresponding author: esappey@gmail.com
}

Thus, gender-specific (GS) components were introduced to address these issues. Instead of simply increasing the number of femoral implants with similar ML to AP ratios, the GS component is designed to better accommodate females' anatomic differences with a narrower ML dimension for any given dimension. Moreover, to better match the native female anatomy the anterior flange thickness was reduced and the angle of the trochlear groove was increased $[8,22]$.

Two systematic reviews [23, 24] and meta-analysis were performed comparing clinical and radiographic results of TKA in female patients receiving standard unisex or GS prostheses. The authors of these two studies reported a lower femoral component overhang rate in the gender-specific group without any influence on clinical results. They concluded that gender-specific prostheses did not appear to confer any benefit in terms of clinician-reported and patient-reported outcomes for the female knee. 
Thus, we decided to perform a recent systematic review of the literature in order to identify all new studies on this specific topic. We compared the clinical and radiographic outcomes of TKA in female patients receiving GS prostheses or standard unisex prostheses. Our outcome variables included clinical rating scores, radiological outcomes, or complications at a minimum follow-up of two years.

\section{Methods}

\section{Literature search strategy}

For this study, the Preferred Reporting Items for Systematic Reviews and Meta-Analyses (PRISMA) guidelines were followed [25]. A primary electronic search was performed using PubMed, Ovid Medline, and Cochrane library from their dates of inception to the 15th February 2020. To maximize search strategy sensitivity, the authors combined the terms "knee", "arthroplasty", "replacement", "gender specific", "conventional", "standard", and "unisex design" when searching in the title, abstract, keywords, and MeSH fields. A secondary search was performed examining the references cited in the articles found in the primary search. All articles were reviewed by two authors independently following this systematic approach. Each reviewer was blinded with regard to the determination of the other reviewer. Ethical approval was not necessary in this study as it only analyzed current studies and did not collect individual patient data. No external funding was received for this project.

\section{Selection criteria}

Only prospective randomized controlled trials (PRCTs) comparing GS implants to conventional implants in TKA were included. All studies included a gender-specific implant group and a conventional or standard implant group with a minimum of 10 TKAs in each group and a minimum follow-up of two years. The authors included studies in the final analysis, if they reported clinical outcome scores, complications, or postoperative radiographic assessment. When several studies reported the results of the same patient series with different followups, only the last study with the longest follow-up was analyzed. All publications included were limited to those written in the English language, involving human subjects and full-text availability for the articles. Reviews, duplicate studies, case reports, noncomparative studies, expert opinions, letters, and conference presentations were excluded.

\section{Data extraction}

All the relevant data were extracted from article text, figures, and tables. Two investigators independently reviewed and extracted data from the retrieved articles. Discrepancies at the full-text stage were resolved by consensus between the two reviewers. If a consensus could not be reached, a third, more senior reviewer helped to resolve the discrepancy. The two independent reviewers collected information regarding the publication origin, publication date, authors, patient demographics (age, sample size, and body mass index (BMI)), prosthetic designs, and outcome measurements.

The primary outcomes were the clinical and radiological results. The clinical results included range of motion (ROM), the Knee Society score (KSS) [26], Hospital for special surgery (HSS) score, Western Ontario, and McMaster Universities Osteoarthritis Index (WOMAC) [27] satisfaction and preference. The radiological results included the alignment of the limb (femorotibial angle), the patellar tilt angle, the posterior condylar offset, or radiolucent lines.

\section{Quality assessment}

A risk-of-bias evaluation was performed using the Cochrane Collaboration tool [28]. Seven domain-based evaluations related to risk of bias were performed, including blinding of the participants and personnel (performance bias), evaluation for random sequence generation (selection bias), blinding of the assessors (defection bias), allocation concealment (selection bias), selective reporting (reporting bias), incomplete outcome data (attrition bias), and other biases. The overall quality of each study was evaluated as a "low risk of bias", a "high risk of bias", or an "unclear risk of bias".

A modified Jadad score was used for the quality evaluation of PRCTS including data analysis, blinding, randomization, withdrawal, adverse reactions, and inclusion criteria. Lowquality studies scored from 0 to 3 and high-quality studies scored from 4 to 8 .

\section{Statistical analysis}

Descriptive statistics, such as means, ranges, and measures of variance (standard deviations, 95\% confidence intervals (CI)), are presented where applicable. No meta-analysis was performed.

\section{Results}

The selection procedure is shown in Figure 1. A total of 1052 studies were identified by using our primary and secondary search strategy. After exclusion of duplicate studies, a total of 970 studies remained for further screening. Examination of title/abstracts excluded 948 records, and a further 19 were excluded after the studies were examined closely. Thus, three PRCTs were included [29-31] and were published between 2010 and 2012. Characteristics of the studies included are reported in Table 1.

\section{Risk of bias and quality of evidence}

The results of the risk-of-bias assessment of the studies are reported in Figure 2. There was an unclear risk of bias in two studies in blinding the outcome assessment (detection bias). There was an unclear risk of bias in one study in allocation concealment (selection bias). There was an unclear risk of bias in one study in blinding the participants and personnel (performance bias). There was an unclear risk of bias for the category "other bias" in the three studies. We did not find any 


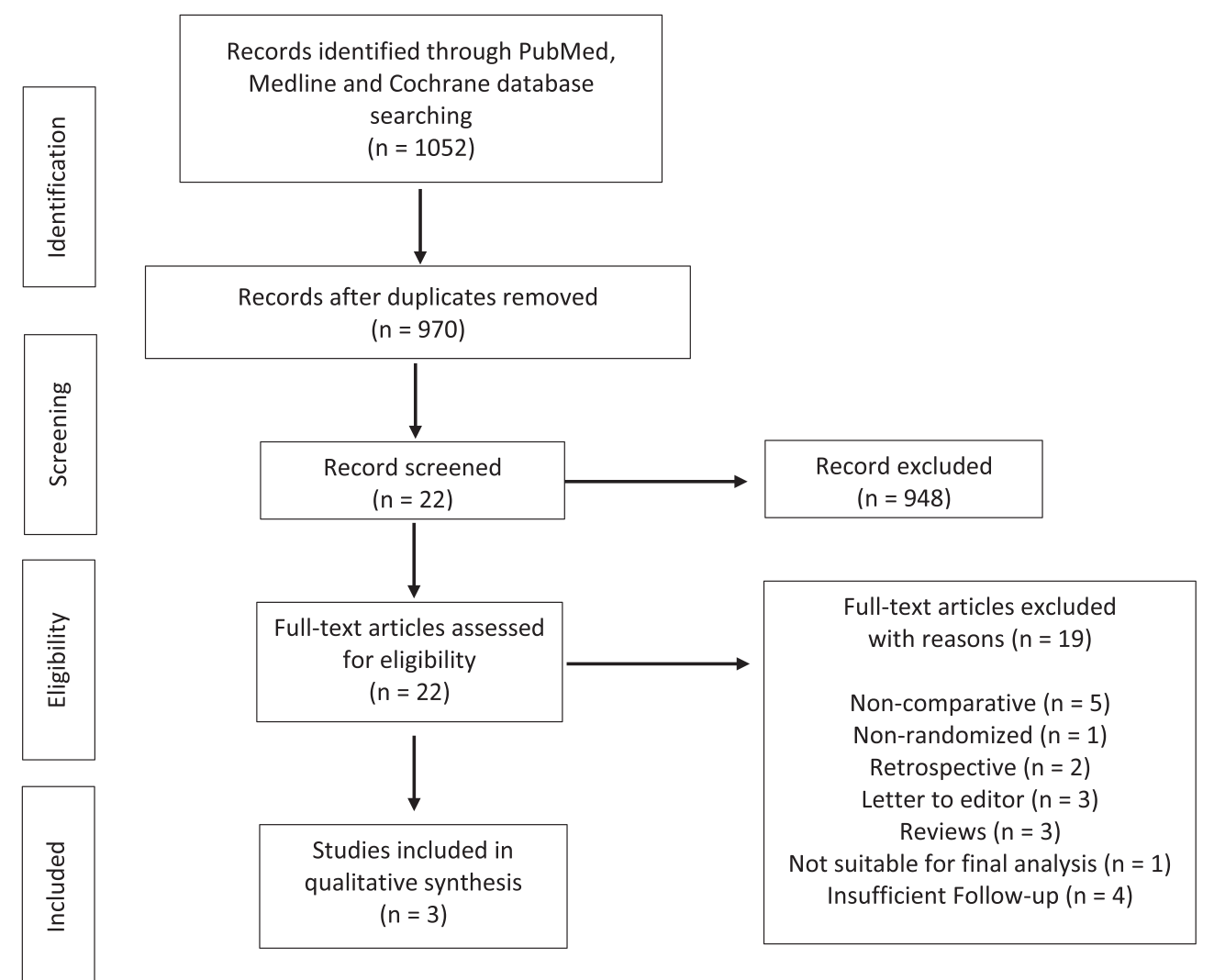

Figure 1. Flow chart.

Table 1. Characteristic of the studies.

\begin{tabular}{|c|c|c|c|c|c|c|c|c|c|c|c|}
\hline \multirow[t]{2}{*}{ Studies } & \multirow[t]{2}{*}{ Location } & \multirow[t]{2}{*}{$\begin{array}{l}\text { Study } \\
\text { design }\end{array}$} & \multirow{2}{*}{$\begin{array}{c}\text { Minimum } \\
\text { follow-up } \\
(\mathrm{m})\end{array}$} & \multicolumn{2}{|c|}{$\begin{array}{c}\text { Sample } \\
\text { size }\end{array}$} & \multirow[t]{2}{*}{$\begin{array}{c}\text { Mean } \\
\text { age }\end{array}$} & \multirow[t]{2}{*}{$\begin{array}{c}\text { BMI } \\
\text { (mean) }\end{array}$} & \multirow[t]{2}{*}{ Prosthesis design } & \multirow[t]{2}{*}{$\begin{array}{c}\text { Clinical } \\
\text { measurements }\end{array}$} & \multirow[t]{2}{*}{$\begin{array}{l}\text { Radiological } \\
\text { measurements }\end{array}$} & \multirow[t]{2}{*}{$\begin{array}{c}\text { Other } \\
\text { measurements }\end{array}$} \\
\hline & & & & GS & Conv & & & & & & \\
\hline $\begin{array}{l}\text { Kim } \\
\quad \text { et al. } \\
{[29]}\end{array}$ & $\begin{array}{l}\text { South } \\
\text { Korea }\end{array}$ & PRCT & 37 & 138 & 138 & 71.2 & 27.3 & $\begin{array}{l}\text { GS: NexGen gender- } \\
\text { specific CR-flex, } \\
\text { cemented, all PR } \\
\text { Conv: NexGen standard } \\
\text { CR-flex, } \\
\text { cemented, all PR }\end{array}$ & $\begin{array}{l}\text { WOMAC, KSS, } \\
\text { ROM, pain, } \\
\text { satisfaction, } \\
\text { preference }\end{array}$ & $\begin{array}{l}\text { Radiographic } \\
\text { outcomes }\end{array}$ & Complications \\
\hline $\begin{array}{l}\text { Kim } \\
\quad \text { et al. } \\
{[30]}\end{array}$ & $\begin{array}{l}\text { South } \\
\text { Korea }\end{array}$ & PRCT & 24 & 85 & 85 & 69.7 & 27.1 & $\begin{array}{l}\text { GS: NexGen gender- } \\
\text { specific posterior } \\
\text { cruciate-substituting } \\
\text { flex, cemented, } \\
\text { all PR } \\
\text { Conv: NexGen standard } \\
\text { posterior cruciate- } \\
\text { substituting flex, } \\
\text { cemented, all PR }\end{array}$ & $\begin{array}{l}\text { WOMAC, HSS, } \\
\text { KSS, ROM, pain, } \\
\text { satisfaction, } \\
\text { preference }\end{array}$ & $\begin{array}{l}\text { Radiographic } \\
\text { outcomes }\end{array}$ & Complications \\
\hline $\begin{array}{l}\text { Song } \\
\quad \text { et al. } \\
{[31]}\end{array}$ & $\begin{array}{l}\text { South } \\
\text { Korea }\end{array}$ & PRCT & 24 & 46 & 46 & 68.8 & 26.8 & $\begin{array}{l}\text { GS: NexGen gender- } \\
\text { specific CR-flex, } \\
\text { cemented, no PR } \\
\text { Conv: NexGen standard } \\
\text { CR-flex, cemented, } \\
\text { no PR }\end{array}$ & $\begin{array}{l}\text { WOMAC, } \\
\text { HSS, ROM, } \\
\text { preference }\end{array}$ & $\begin{array}{c}\text { Radiographic } \\
\text { outcomes }\end{array}$ & \\
\hline
\end{tabular}

PRCT: prospective randomized controlled trial, GS: gender-specific, Conv: conventional, CR: cruciate-retaining, PR: patella resurfacing, WOMAC: Western Ontario and McMaster Universities Osteoarthritis Index, KSS: knee society score, ROM: range of motion, HSS: Hospital for Special Surgery knee score. 


\section{Risk of bias graph}

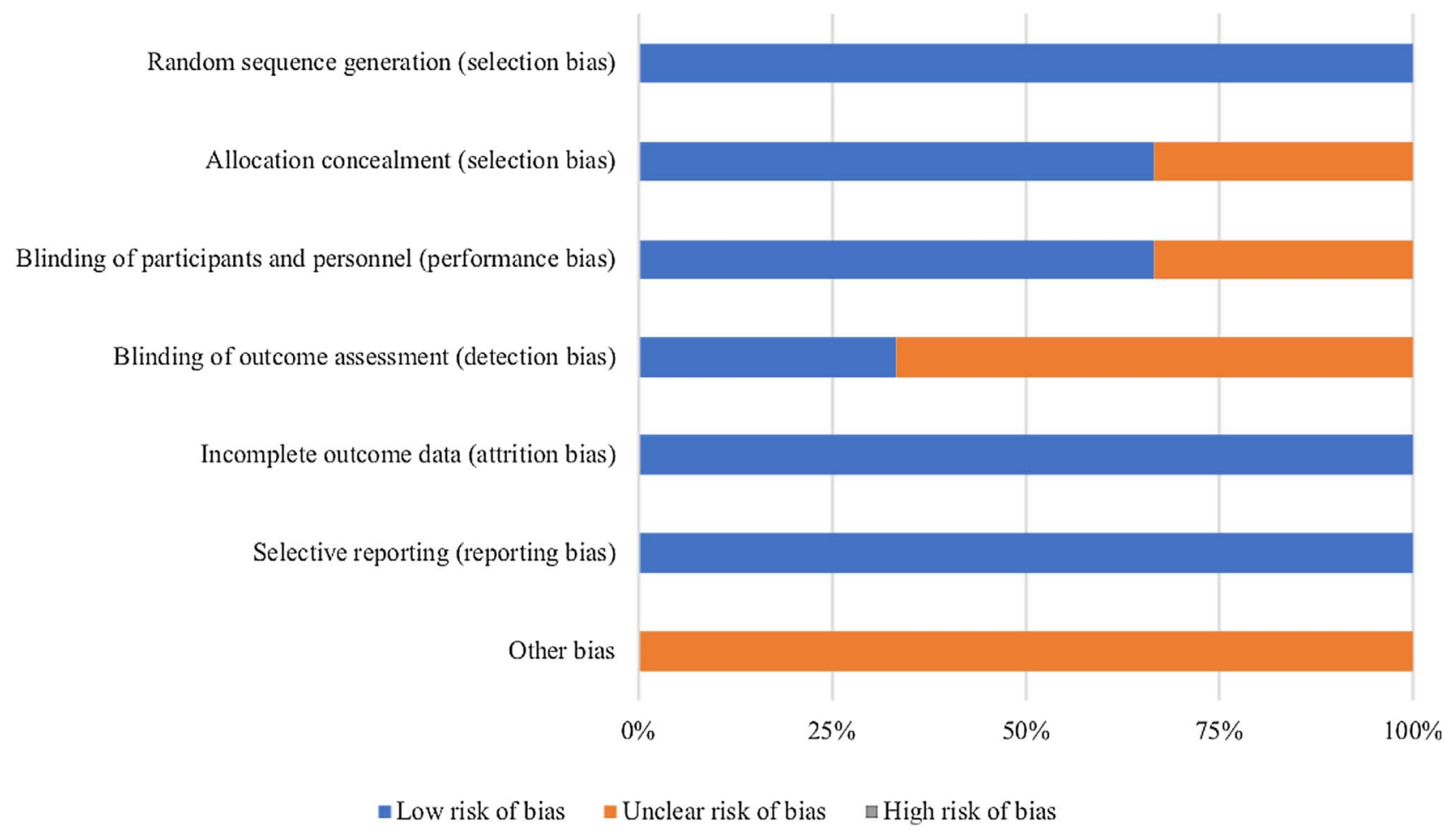

\begin{tabular}{|l|c|c|c|}
\cline { 2 - 4 } \multicolumn{1}{c|}{} & \begin{tabular}{c} 
Kim 2010 \\
\multicolumn{1}{c|}{}
\end{tabular} & $\begin{array}{c}\text { Kim 2010 } \\
(29)\end{array}$ & $\begin{array}{c}\text { Song 2012 } \\
(31)\end{array}$ \\
\hline Random sequence generation (selection bias) & + & + & + \\
\hline Allocation concealment (selection bias) & + & + & $?$ \\
\hline Blinding of participants and personnel (performance bias) & + & $?$ & + \\
\hline Blinding of outcome assessment (detection bias) & + & $?$ & $?$ \\
\hline Incomplete outcome data (attrition bias) & + & + & + \\
\hline Selective reporting (reporting bias) & + & + & + \\
\hline Other bias & $?$ & $?$ & $?$ \\
\hline
\end{tabular}

Figure 2. Risk of bias graph; "+ or plus" indicates a low risk of bias; "- or minus" indicates a high risk of bias; and "? or question mark" indicates unclear of unknown risk of bias.

other apparent bias in any of the included studies. The quality evaluation scores of the studies are shown in Table 2. Two studies included in this systematic review were given scores of 5 and one study had a score of 7 . Thus, after examination, the three included studies were of very high quality and had a low risk of bias.

\section{Clinical results}

For the three studies, clinical results were significantly improved postoperatively in both groups (gender-specific and conventional) without showing any significant difference between groups for all scores [29-31]. All clinical results are reported in Table 3. Two studies reported postoperative complication rate and no significant difference was found between GS and conventional groups at the last follow-up.

\section{Radiological results}

Two studies reported radiolucent lines of $<1 \mathrm{~mm}$ in their study without any significant differences between groups. Two studies reported prostheses overhang. Gender-specific TKA significantly reduced the overhang rate compared to conventional TKA. Indeed, Kim et al. [29] showed in the group with conventional implants 14 knees had an overhang (mean, $1.7 \mathrm{~mm}$; range, $1-4 \mathrm{~mm}$ ), and $24 \mathrm{knees}$ had an under-coverage 
Table 2. Modified Jadad-score.

\begin{tabular}{|c|c|c|c|}
\hline & Kim et al. [29] & Kim et al. [30] & Song et al. [31] \\
\hline Was the study described as randomized? & Yes & Yes & Yes \\
\hline Was the method of randomization appropriate? & Yes & Yes & No \\
\hline Was the study described as blinded? & No & No & Yes \\
\hline Was the method of blinding appropriate? & No & No & Yes \\
\hline Was there a description of withdrawals or dropouts? & Yes & Yes & Yes \\
\hline Was there a clear description of the inclusion/exclusion criteria? & Yes & Yes & Yes \\
\hline Was the method used to assess adverse effects described? & No & No & Yes \\
\hline Was the method of statistical analysis described? & Yes & Yes & Yes \\
\hline Total score & 5 & 5 & 7 \\
\hline
\end{tabular}

Table 3. Clinical results at the last follow up ( $\mathrm{SD}=$ standard deviation).

\begin{tabular}{|c|c|c|c|c|}
\hline Studies & $\begin{array}{c}\text { Clinical } \\
\text { assessment }\end{array}$ & $\begin{array}{c}\text { Gender-specific prosthesis } \\
\text { mean } \pm \text { SD (range) }\end{array}$ & $\begin{array}{c}\text { Conventional prosthesis } \\
\text { mean } \pm \text { SD (range) }\end{array}$ & $p$-value \\
\hline \multirow[t]{7}{*}{ Kim et al. [29] } & KSS knee & $93(70-100)$ & $94(70-100)$ & 0.69 \\
\hline & KSS functional & $84(60-100)$ & $83(60-100)$ & 0.322 \\
\hline & Flexion & $124(85-140)$ & $126(85-140)$ & 0.002 \\
\hline & Pain & $46.6(20-50)$ & $46.8(20-50)$ & 0.667 \\
\hline & Satisfaction & $7.9 \pm 2.1$ & $8.1 \pm 1.9$ & 0.187 \\
\hline & Preference & $14(10.1 \%)$ & $12(8.7 \%)$ & $>0.05$ \\
\hline & Complications & 1 & 1 & $>0.05$ \\
\hline \multirow[t]{9}{*}{ Kim et al. [30] } & WOMAC & $35.7(5-61)$ & $36.6(4-69)$ & 0.189 \\
\hline & HSS & $91.2(77-100)$ & $90.7(84-100)$ & 0.252 \\
\hline & KSS knee & $96.5(83-100)$ & $95.5(81-100)$ & 0.424 \\
\hline & KSS functional & $84.8(60-100)$ & $84.8(60-100)$ & $>0.05$ \\
\hline & Flexion & $126(85-140)$ & $125(80-140)$ & 0.739 \\
\hline & Pain & $46.3(40-50)$ & $45.1(40-50)$ & 0.838 \\
\hline & Satisfaction & $8.1 \pm 1.9$ & $8.3 \pm 1.7$ & 0.783 \\
\hline & Preference & $6(7 \%)$ & $8(9 \%)$ & $>0.05$ \\
\hline & Complications & 1 & 1 & $>0.05$ \\
\hline \multirow[t]{4}{*}{ Song et al. [31] } & WOMAC & $31.6 \pm 8.5(24-52)$ & $32.6 \pm 9.2(24-58)$ & 0.58 \\
\hline & HSS & $92.7 \pm 8.0(75-100)$ & $92.1 \pm 8.7(67-100)$ & 0.75 \\
\hline & Flexion & $131.1 \pm 9.2$ & $133.7 \pm 19.2$ & 0.16 \\
\hline & Preference & $10(10.9 \%)$ & $7(7.6 \%)$ & 0.59 \\
\hline
\end{tabular}

KSS: knee society score, WOMAC: Western Ontario and McMaster Universities Osteoarthritis Index, HSS: Hospital for Special Surgery knee score.

(mean, $1.6 \mathrm{~mm}$; range, 1-5 mm); and in the group with a gender-specific implant, 123 knees had an under-coverage (mean, $3.7 \mathrm{~mm}$; range, 1-11 mm). Kim et al. [30], in another study, showed in the group with conventional implants 10 knees had an overhang (mean, $1.4 \pm 0.7 \mathrm{~mm}$; range, $1-3 \mathrm{~mm}$ ), and 24 knees had an under-coverage (mean, $1.1 \pm 0.3 \mathrm{~mm}$; range, 1-2 mm); and in the group with a gender-specific implant, 71 knees had an under-coverage (mean, $2.8 \pm 1.3 \mathrm{~mm}$; range, 1-7 mm). No significant difference was found between both groups for patellar tilt angle. All radiographic results are reported in Table 4.

\section{Discussion}

This review is a recent update of all comparative studies between GS implants and standard unisex implants with a minimum follow-up of two years. All studies included were level I and therefore of very high quality. The principal findings of this systematic review were as follows: the clinical results of GS TKA were similar to those of conventional TKA and a significantly reduced overhang rate was found for GS prostheses compared to conventional implants. Our study is more strict on inclusion criteria compared to previous literature review on this topic and may be more robust in its conclusion.

GS knee prostheses were introduced based on the assumption that TKA outcomes might be inferior in women compared to men when using standard prostheses, although one study reported that women achieved similar or even better results in terms of pain, satisfaction, range of motion, satisfaction, and implant survival when standard implants were used [32]. Standard unisex implants may lead to overhang, which can be resolved by using GS implants for women, as they have a different distal femoral aspect ratio and a higher $Q$-angle. 
Table 4. Radiological results at the last follow up ( $\mathrm{SD}=$ Standard deviation).

\begin{tabular}{|c|c|c|c|c|}
\hline Studies & $\begin{array}{c}\text { Radiological } \\
\text { assessment }\end{array}$ & $\begin{array}{c}\text { Gender-specific prosthesis } \\
\text { mean } \pm \text { SD (range) }\end{array}$ & $\begin{array}{c}\text { Conventional prosthesis } \\
\text { mean } \pm \mathrm{SD} \text { (range) }\end{array}$ & $p$-value \\
\hline Kim et al. [29] & $\begin{array}{c}\text { HKA }\left(^{\circ}\right) \\
\text { TS }\left(^{\circ}\right) \\
\text { PCO (mm) } \\
\text { PTA }\left(^{\circ}\right) \\
\text { Radiolucent line } \\
\text { Overhang } \\
\text { Under-coverage }\end{array}$ & $\begin{array}{c}186.6(182 \text { to } 187) \\
7(2 \text { to } 12) \\
0.3(0 \text { to } 18) \\
3.8 \pm 1.2 \\
11(8.0 \%) \\
0(0 \%) \\
123(89 \%)\end{array}$ & $\begin{array}{c}186.3(183 \text { to } 187) \\
7.6(1 \text { to } 14) \\
-0.3(-2 \text { to } 0) \\
3.3 \pm 1.7 \\
12(8.7 \%) \\
14(10.1 \%) \\
44(31.9 \%)\end{array}$ & $\begin{array}{l}0.970 \\
0.492 \\
0.148 \\
0.919 \\
>0.05 \\
<0.001 \\
<0.001\end{array}$ \\
\hline Kim et al. [30] & $\begin{array}{c}\text { HKA }\left(^{\circ}\right) \\
\text { TS }\left(^{\circ}\right) \\
\text { PCO (mm) } \\
\text { PTA }\left({ }^{\circ}\right) \\
\text { Radiolucent line } \\
\text { Overhang } \\
\text { Under-coverage }\end{array}$ & $\begin{array}{c}186.4(181.5 \text { to } 188) \\
7(-2 \text { to } 14) \\
0.3(0 \text { to } 1) \\
3.6 \pm 1.6 \\
6(7 \%) \\
0(0 \%) \\
71(84 \%)\end{array}$ & $\begin{array}{c}185.8(182 \text { to } 187) \\
7.6(1 \text { to } 12) \\
-0.5(-2 \text { to }-1) \\
3.8 \pm 1.3 \\
17(8 \%) \\
10(12 \%) \\
24(28 \%)\end{array}$ & $\begin{array}{c}0.901 \\
0.699 \\
0.151 \\
0.873 \\
1.0 \\
0.0011 \\
<0.001\end{array}$ \\
\hline Song et al. [31] & $\begin{array}{c}\text { HKA }\left(^{\circ}\right) \\
\text { TS }\left(^{\circ}\right) \\
\text { PCO }(\mathrm{mm}) \\
\text { ACO }(\mathrm{mm}) \\
\text { PTA }\left(^{\circ}\right)\end{array}$ & $\begin{array}{c}185.96 \pm 2.2 \\
7.6 \pm 3.1 \\
1.4 \pm 3.2 \\
1.3 \pm 2.9 \\
6.0 \pm 3.8\end{array}$ & $\begin{array}{c}185.7 \pm 2.1 \\
6.2 \pm 2.5 \\
0.7 \pm 4.0 \\
0.2 \pm 1.5 \\
7.7 \pm 4.4\end{array}$ & $\begin{array}{l}0.54 \\
0.08 \\
0.05 \\
0.08 \\
0.83\end{array}$ \\
\hline
\end{tabular}

HKA: hip-knee-ankle angle, TS: tibial slope, PCO: posterior condylar offset, PTA: patellar tilt angle, ACO: anterior condylar offset.

Indeed, using GS prosthesis should potentially reduce the incidence of overhang and therefore, in theory, reduce postoperative medial and lateral knee pain due to soft-tissue irritation. Mahoney and Kinsey [21] showed that significantly more women had lateral and medial overhang than men when a conventional prosthesis was used. They also found that an overhang of the femoral component $\geq 3 \mathrm{~mm}$ was related to post-operative knee pain. When a GS prosthesis was implanted in women, Clarke and Hentz [18] found a decrease in the occurrence of overhang (17\% vs. $5 \%)$. In this systematic review, two studies reported a significantly reduced femoral component overhang in the GS group (0 mm vs. $1.4-1.7 \mathrm{~mm}$ ) without any significant difference in clinical outcomes between groups. The observed overhang, which was less than $3 \mathrm{~mm}$, may explain the absence of significant clinical difference between groups by being insufficient. Furthermore, it is important to note that in the GS group, a higher incidence of underhang was observed, which exposed more cancellous bone and could be a source of higher perioperative blood loss, and may induce increased osteolysis from wear debris at longer follow-up [10, 29, 30].

Overstuffing of the anterior knee compartment may be associated with reduce ROM and pain. Women having a less prominent native anterior femoral condyle, using a standard unisex TKA could possibly lead to overstuffing [14, 33]. Despite the fact that reduced height of the anterior femoral implant flange and the deeper trochlear groove improve patellar tracking in the GS design and help prevent overstuffing of the patellofemoral joint, we did not find any significant difference in postoperative pain and ROM between groups.

On the other hand, several studies refuted the assumption that women have worse outcomes than men using standard unisex TKA designs [3, 32-34]. Indeed, some studies showed similar, or even better, results between women and men [5, 32, 34]. Merchant et al. [32], in a systematic review, reported no evidence of anatomical differences between male and female knees that would justify a female-specific design. The anatomical differences between female and male knees can be explained by the smaller size and height of women on average, not by their gender. Bellemans et al. [35] reported that the shape of the knee is not only dependent on gender, but also on the morphotype of the patient. Piriou et al. [36] showed similar findings in their study, with findings that the distal femoral epiphysis was only related to femoral length, independent of gender.

Several limitations should be discussed. Firstly, we only found three relevant studies that compared GS with conventional TKA with a minimum follow-up of two years. Thus, the follow-up period was short. However, earlier studies have revealed that the range of movement and satisfaction reaches a plateau beyond one year [37, 38]. Secondly, our data analyzed only a single implant design (Zimmer Gender). These results may not be applied to other TKA designs. Finally, all studies included were already included in previous literature reviews and no new papers or data since 2012 were included in our analysis as nothing has been published since.

\section{Conclusion}

In our systematic review, despite less femoral prosthesis overhang rate with GS prostheses, we conclude that gender-specific implants in female total knee replacements showed no clinical benefit over standard unisex implants. Good clinical results with significant improvement were observed with both designs. There is a notable absence of new studies on this subject in recent years, and further research needs to be performed using 
various gender-specific implant designs to further define the role of gender-specific implants.

\section{Conflict of interest}

Prof. Sébastien Lustig has performed consultancy work for Medacta, Heraeus, Corin, Amplitude, Groupe Lépine, Depuy Synthes, Smith \& Nephew, Stryker. Prof. Sébastien Lustig and Prof Elvire Servien receive institutional research support from Corin and Amplitude. Prof. Sébastien Lustig is a board member of KSSTA and Maitrise Orthopédique. The other authors declare that they have no conflicts of interest.

\section{References}

1. Bourne RB, Chesworth BM, Davis AM, et al. (2010) Patient satisfaction after total knee arthroplasty: Who is satisfied and who is not? Clin Orthop 468, 57-63.

2. Kurtz S, Ong K, Lau E, et al. (2007) Projections of primary and revision hip and knee arthroplasty in the United States from 2005 to 2030. J Bone Joint Surg Am 89, 780-785.

3. Ritter MA, Wing JT, Berend ME, et al. (2008) The clinical effect of gender on outcome of total knee arthroplasty. J Arthroplasty 23, 331-336.

4. Rand JA, Ilstrup DM (1991) Survivorship analysis of total knee arthroplasty. Cumulative rates of survival of 9200 total knee arthroplasties. J Bone Joint Surg Am 73, 397-409.

5. Parsley BS, Bertolusso R, Harrington M, et al. (2010) Influence of gender on age of treatment with TKA and functional outcome. Clin Orthop 468, 1759-1764.

6. Barrett WP (2006) The need for gender-specific prostheses in TKA: Does size make a difference? Orthopedics 29, S53-55.

7. Booth RE (2006) Sex and the total knee: Gender-sensitive designs. Orthopedics 29, 836-838.

8. Greene KA (2007) Gender-specific design in total knee arthroplasty. J Arthroplasty 22, 27-31.

9. Chin KR, Dalury DF, Zurakowski D, Scott RD (2002) Intraoperative measurements of male and female distal femurs during primary total knee arthroplasty. J Knee Surg 15, 213-217.

10. Hitt K, Shurman JR, Greene K, et al. (2003) Anthropometric measurements of the human knee: correlation to the sizing of current knee arthroplasty systems. J Bone Joint Surg Am, 85-A (Suppl. 4), 115-122.

11. Poilvache PL, Insall JN, Scuderi GR, Font-Rodriguez DE (1996) Rotational landmarks and sizing of the distal femur in total knee arthroplasty. Clin Orthop 331, 35-46.

12. Vaidya SV, Ranawat CS, Aroojis A, Laud NS (2000) Anthropometric measurements to design total knee prostheses for the Indian population. J Arthroplasty 15, 79-85.

13. Conley S, Rosenberg A, Crowninshield R (2007) The female knee: Anatomic variations. J Am Acad Orthop Surg 15(Suppl. 1), S31-36.

14. Fehring TK, Odum SM, Hughes J, et al. (2009) Differences between the sexes in the anatomy of the anterior condyle of the knee. J Bone Joint Surg Am 91, 2335-2341.

15. Hsu RW, Himeno S, Coventry MB, Chao EY (1990) Normal axial alignment of the lower extremity and load-bearing distribution at the knee. Clin Orthop 255, 215-227.
16. Woodland LH, Francis RS (1992) Parameters and comparisons of the quadriceps angle of college-aged men and women in the supine and standing positions. Am J Sports Med 20, 208-211.

17. Chaichankul C, Tanavalee A, Itiravivong P (2011) Anthropometric measurements of knee joints in Thai population: Correlation to the sizing of current knee prostheses. Knee 18, 5-10.

18. Clarke HD, Hentz JG (2008) Restoration of femoral anatomy in TKA with unisex and gender-specific components. Clin Orthop 466, 2711-2716.

19. Yan M, Wang J, Wang Y, et al. (2014) Gender-based differences in the dimensions of the femoral trochlea and condyles in the Chinese population: Correlation to the risk of femoral component overhang. Knee 21, 252-256.

20. Lo C-S, Wang S-J, Wu S-S (2003) Knee stiffness on extension caused by an oversized femoral component after total knee arthroplasty: A report of two cases and a review of the literature. J Arthroplasty 18, 804-808.

21. Mahoney OM, Kinsey $\mathrm{T}$ (2010) Overhang of the femoral component in total knee arthroplasty: Risk factors and clinical consequences. J Bone Joint Surg Am 92, 1115-1121.

22. Booth RE (2006) The gender-specific (female) knee. Orthopedics 29, 768-769.

23. Cheng T, Zhu C, Wang J, et al. (2014) No clinical benefit of gender-specific total knee arthroplasty. Acta Orthop 85, 415-421.

24. Xie X, Lin L, Zhu B, et al. (2014) Will gender-specific total knee arthroplasty be a better choice for women? A systematic review and meta-analysis. Eur J Orthop Surg Traumatol Orthop Traumatol 24, 1341-1349.

25. Liberati A, Altman DG, Tetzlaff J, et al. (2009) The PRISMA statement for reporting systematic reviews and meta-analyses of studies that evaluate healthcare interventions: Explanation and elaboration. BMJ 339, b2700.

26. Insall JN, Dorr LD, Scott RD, Scott WN (1989) Rationale of the Knee Society clinical rating system. Clin Orthop 248, 13-14.

27. Bellamy N, Buchanan WW (1986) A preliminary evaluation of the dimensionality and clinical importance of pain and disability in osteoarthritis of the hip and knee. Clin Rheumatol 5, 231-241.

28. Higgins JPT, Altman DG, Gøtzsche PC, et al. (2011) The Cochrane Collaboration's tool for assessing risk of bias in randomised trials. BMJ 343, d5928.

29. Kim Y-H, Choi Y, Kim J-S (2010) Comparison of standard and gender-specific posterior-cruciate-retaining high-flexion total knee replacements: A prospective, randomised study. J Bone Joint Surg Br 92, 639-645.

30. Kim Y-H, Choi Y, Kim J-S (2010) Comparison of a standard and a gender-specific posterior cruciate-substituting high-flexion knee prosthesis: A prospective, randomized, short-term outcome study. J Bone Joint Surg Am 92, 1911-1920.

31. Song EK, Jung WB, Yoon TR, et al. (2012) Comparison of outcomes after bilateral simultaneous total knee arthroplasty using gender-specific and unisex knees. J Arthroplasty 27, 226-231.

32. Merchant AC, Arendt EA, Dye SF, et al. (2008) The female knee: Anatomic variations and the female-specific total knee design. Clin Orthop 466, 3059-3065.

33. Mihalko W, Fishkin Z, Krackow K, Krakow K (2006) Patellofemoral overstuff and its relationship to flexion after total knee arthroplasty. Clin Orthop 449, 283-287.

34. O'Connor MI (2011) Implant survival, knee function, and pain relief after TKA: Are there differences between men and women? Clin Orthop 469, 1846-1851. 
35. Bellemans J, Carpentier K, Vandenneucker H, et al. (2010) The John Insall Award: Both morphotype and gender influence the shape of the knee in patients undergoing TKA. Clin Orthop 468, 29-36.

36. Piriou P, Mabit C, Bonnevialle P, et al. (2014) Are genderspecific femoral implants for total knee arthroplasty necessary? J Arthroplasty 29, 742-748.
37. Kim Y-H, Sohn K-S, Kim J-S (2005) Range of motion of standard and high-flexion posterior stabilized total knee prostheses. A prospective, randomized study. J Bone Joint Surg Am 87, 1470-1475.

38. Ritter MA, Berend ME, Harty LD, et al. (2004) Predicting range of motion after revision total knee arthroplasty: Clustering and log-linear regression analyses. J Arthroplasty 19, 338-343.

Cite this article as: Sappey-Marinier E, Swan J, Batailler C, Servien E \& Lustig S (2020) No clinical benefit from gender-specific total knee replacement implants: a systematic review. SICOT-J 6, 25 